\title{
Self-Actualization as a Predictor of Flourishing
}

\section{Evanytha}

Faculty of Psychology, Universitas Pancasila, Jakarta, Indonesia

*Corresponding author:

Evanytha

Faculty of Psychology, Universitas Pancasila

Jl. Serengseng Sawah, Jagakarsa

South Jakarta - Indonesia 12640

Tel: +62 78882874

Email address: evaoktober@yahoo.com 


\title{
Self-Actualization as a Predictor of Flourishing
}

\begin{abstract}
Psychology has directed much of its attention to repairing the damage within certain disease models and has therefore neglected to consider the effects that a fulfilled individual can have on the prevention of pathologies. It has been observed that high levels of well-being, or flourishing, can act as a buffer against mental illness. Flourishing has five pillars; positive emotions, engagement, relationships, meaning in life, and accomplishments (PERMA). The eudaimonic approach to wellbeing suggests that psychological health can be achieved by fulfilling one's potential or realizing one's true nature, and self-actualization refers to the desire for selffulfillment and the actualization of potential. Therefore, this study examined the degree to which self-actualization was a predictor of the PERMA flourishing dimensions. The PERMA-Profiler was used to measure flourishing and the Short Index of Self-Actualization was used to measure self-actualization in 147 undergraduate students aged from 18 to 24 years. Simple linear regression analysis was then used to analyze the data from which it was found that self-actualization significantly and negatively contributed to all flourishing dimensions; $18.3 \%$ to Positive Emotions, $15.4 \%$ to Engagement, $16.6 \%$ to Relationships, $19.7 \%$ to Meaning, and $15.4 \%$ to Accomplishment; which was speculated to be because of the tendency of highly self-actualized individuals to maintain their individuality even in interdependent, collectivist cultures, have a greater concern about the future than fully engaging in the present, and pursuing goals to gain rewards from their group rather than to realize their true nature or for self-fulfillment.
\end{abstract}

Keywords: flourishing, self-actualization, well-being, PERMA

\section{Introduction}

Psychology has directed much of its attention to repairing the damage within a certain disease model and has therefore neglected to consider the effects that a fulfilled individual can have on the prevention of pathologies. As it has been found that human strength can buffer mental illness (Seligman \& Csikszentmihalyi, 2014), psychology needs to be able to consider the value of human strength rather than just weakness and pathology, and treatment needs to focus on repairing the broken and nurturing the best within individuals. This study examined the prevention of psychological pathologies through the development of psychological strength in people with a high level of well-being.

Well-being has been found to have beneficial consequences at the individual, organizational, and national levels. Domestic policy generally focuses on economic indicators and outcomes, which mislead people about what the society values; that is, while economic growth is very important in the early stages of development, as the wealth of societies increases, the differences in well-being are more related to social relationships and enjoyment at work (Diener, 2004).

The positive psychological term, flourishing, therefore, was developed to describe high levels of well-being (Hone, Jarden, Schofield, \& Duncan, 2014). Reference [4] defined flourishing as 
the optimal state of an individual's psychosocial functioning that rests on five pillars; Positive emotion (P), Engagement (E), Relationships (R), Meaning (M), and Accomplishment (A) (PERMA); all of which are fundamental to human well-being (Seligman, 2011).

According to Butler and Kern (2016), rather than using one model as the best model for wellbeing, to better understand and measure the construct, Butler and Kern (2016) focused on the five PERMA domains to measure flourishing. Flourishers have been identified as people that have high levels of hedonic and eudaimonic well-being (Schotanus-Dijkstra et al., 2016); consequently, there have been both hedonic and eudemonic approaches developed to examine well-being. The hedonic approaches have focused on pleasure and happiness, with subjective well-being such as life satisfaction, the absence of negative affect, and the presence of positive affect being included in the models (Cooke, Melchert, Connor, 2016). The eudaimonic approaches have focused on the development of good psychological health and well-being by fulfilling one's potential, functioning at an optimal level, or realizing the true nature of individuals (Cooke, Melchert, Connor, 2016). Psychological well-being, therefore, is an example of a eudaimonic approach model to well-being, which has six dimensions in a larger life domain (Ryff \& Keyes, 1995; Cooke, Melchert, \& Connor, 2016).

Self- actualization is the fulfillment of individual potential. Maslow (1987) defined selfactualization as people's desire for self-fulfillment and the actualization of their potential. Maslow also believed that the need for self-actualization only emerged after the lower level needs; physiological needs, and safety needs, love needs, and esteem needs; were satisfied (Maslow, 1987; Faraci \& Cannistraci, 2015).

Although the flourishing and self-actualization concepts have been widely used, they need to be studied within cultural contexts because cultural mores affect the way people see themselves and others (Markus \& Kitayama, 1991), which in turn affects motivation, behavior, and the need for self-actualization (Faraci \& Cannistraci, 2015). As the measurement of well-being has tended to reflect the western individualistic orientation for conceptualizing health and well-being (Cooke, Melchert, \& Connor, 2016), the purpose of this research is to examine self-actualization as a predictor of flourishing in the Indonesian culture.

\section{Literature Review}

\section{A. Flourishing}

Flourishing has been used to describe high levels of well-being (Hone, Jarden, Schofield, \& Duncan, 2014), with flourishers having high levels of both hedonic and eudaimonic well-being (Schotanus-Dijkstra et al., 2016). Flourishing is related to five pillars; positive emotions, engagement, relationships, meaning in life, and accomplishments (PERMA); all of which are the fundamental building blocks to enable flourishing; however, as each of these pillars are pursued for its own sake rather than as a means to achieve another goal, each is measured independently (Seligman, 2011). The five pillars of PERMA are detailed in the following. 
Positive Emotion. Increasing positive emotion can lead to flourishing and is hedonic as it is associated with the degree to which an individual can experience positive emotions. The pillar of positive emotion tends to provide a traditional way to conceptualize happiness (Seligman, 2011), with the PERMA-Profiler of Positive emotions measuring general tendencies toward feeling contentment and joy (Butler \& Kern, 2016).

Engagement. Engagement is experienced when an individual fully uses their skills, strengths, and attention for a challenging task, which then results in "flow," which is when the concentration is fully absorbed in an activity, self-awareness disappears, and there is a distortion in the perception of time, such as when time appears to stop [5]. Flow measures have focused on the degree of intense concentration and absorption (Butler \& Kern, 2016).

Relationships. Relationships are important for flourishing as they provide support and give life a purpose and meaning, which in turn produces an increase in well-being.

Meaning. Serving and belonging to something bigger than the self can give a person a sense of meaning. There are various social institutions that can give meaning and purpose in life, such as religion, family, and work.

Accomplishment. An individual can pursue achievement, competence, success, and mastery in various areas in life, such as the workplace, hobbies, and sports. Accomplishment is pursued for its own sake or in other words, accomplishment is only for accomplishment's sake (Seligman, 2011).

\section{B. Self-actualization}

Maslow's motivational theory organizes human needs in a hierarchy, with physiological needs at the bottom followed by safety needs, belongingness and love needs, esteem needs, and selfactualization needs (Maslow, 1987).Self-actualization refers to a desire for self-fulfillment and the actualization of potential (Maslow, 1987); that is, to become everything that one is capable of becoming. Self-actualization can also be described as "individuals actualizing or realizing their potential and becoming the best they are capable of becoming" (Maslow, 1987; Faraci \& Cannistraci, 2015).

Self-actualized individuals tend to have a more accurate perception of reality, a greater acceptance of their self and others, relative spontaneous behavior, and a focus on problems outside themselves. Self-actualized individuals need more privacy than ordinary people and are relatively independent from their physical and social environments. They have a fresh appreciation of life, a greater tendency for peak experiences, feel a greater kinship and connection to other human beings in general, have humility and respect toward other people, have deeper interpersonal relationships and a compassion for humanity, and have definite moral standards. Self- actualized people focus on the ends rather than the means, have a sense of humor that is real, and never make hostile remarks that hurt another person. Self-actualized individuals have a special kind of creativeness or originality, a healthy personality, and are less enculturated (Maslow, 1987). 
Self-actualized people tend to be autonomous, have an inner detachment from the social environment, and a greater concern about moral issues, such as injustice. They tend to have their own rules, but have no tendency to become rebels (Maslow, 1987). Therefore, their autonomy is related to self-decision, self-government and self-discipline, and being strong and self-moving, being able to make up their own mind, being responsible for themselves and their own destinies as free agents, and having free will (Maslow, 1987).

Self-actualization has been widely studied; however, it needs to be considered within the individual's own cultural context because the view of the self and others is embedded within a person's cultural mores (Markus \& Kitayama, 1991). Self-actualization has been criticized as Maslow gave no real guidance as to the ideal society, culture, and environment needed to develop self-actualization (Faraci \& Cannistraci, 2015). Further, the measurement of wellbeing has tended to be based on western individualistic conceptualizations of health and wellbeing (Cooke, Melchert, \& Connor, 2016). Therefore, the research focus in this study is whether self-actualization contributes to the flourishing (PERMA) dimensions.

\section{Culture and Self}

Markus and Kitayama (in Larsen \& Buss, 2008) explained that people from different cultures differ in how they balance interdependence and independence. The first task is communion or how individuals are affiliated as members in the larger group. The second task of independence is how individuals make themselves different from the group. Independence consists of unique abilities, motives, and personality. While western cultures are characterized by independence, many non-western cultures are characterized by an interdependence that emphasizes interconnectedness within the group, with the self being meaningful only in reference to their larger group. The major cultural tasks for individuals in these cultures are to promote harmony and group unity, with personal desires being constrained. While independence is characterized by as autonomous, stable, coherent self-view that is free from the influences from others, interdependence is characterized by a connected and interpersonally flexible self-view (Markus \& Kitayama in Larsen \& Buss, 2008); therefore, both interdependence and independence affect individual cognition, emotions, and motivation.

Triandis (as cited in Larsen \& Buss, 2008) used the terms individualism and collectivism to explain the distinction between independence and interdependence. Individualism is a sense of the self as autonomous and independent, with a priority given to personal goals, and collectivism is a sense of self that is more connected to a group, with priority given to group goals. People in individualist societies tend to act independently of their group and give priority to their personal goals rather than their group's goals. In contrast, people from collectivist societies are more concerned about relationships and less likely to emphasize their personal accomplishments.

The themes of independence and interdependence affect cognition, emotions, and motivation (Markus \& Kitayama, 1991). Maslow (1987) claimed that self-actualization was a holisticdynamic theory of motivation. If the view of the self as independent or dependent influences 
motivation and self-actualization, which was seen as a form of motivation, then culture must be considered when explaining self-actualization.

There have been attempts to explain the unity behind diversity across cultures by classifying basic needs. However, no evidence has been offered to support the explanation that the basic needs classification is universal even though it has been claimed to apply to ordinary human characteristics (Faraci \& Cannistraci, 2015).

\section{Objective of the Study}

This research examined whether self-actualization contributed to each of the five flourishing (PERMA) dimensions.

\section{E. Hypotheses}

This study tested the hypotheses that self-actualization contributes to the flourishing (PERMA) dimensions.

Ha: Self-actualization contributes to the dimensions of Positive emotion, Engagement, Relationship, Meaning, and Accomplishment.

Ho: Self-actualization does not contribute to dimensions of Positive emotion, Engagement, Relationship, Meaning, and Accomplishment.

\section{Methods}

\section{A. Participants}

This study involved 147 undergraduate male and female student participants aged from 18 to 24 years from various Indonesian ethnicities; Jawa, Minang, Sunda, Bugis, Betawi, Mandailing, Dayak, Melayu, Minahasa, Lampung, Maluku, Karo, and Bima.

\section{B. Instruments}

The PERMA-Profiler. The PERMA-Profiler (Butler \& Kern, 2016) was used to measure the flourishing PERMA domains, and has been found to have good model fit, internal consistency and validity, and is also multidimensional (Butler \& Kern, 2016). Each item was scored on a 6-point Likert scale, from never (1) to always; however, two items were removed from the scale because of low validity. The Cronbach's alpha coefficient and number of items for each of the PERMA-Profiler dimensions are shown in Table 1.

Table 1. Perma-Profiler

\begin{tabular}{|l|l|l|}
\hline \multicolumn{1}{|c|}{ Dimensions } & $\begin{array}{c}\text { Cronbach's } \\
\text { Alpha } \\
\text { Coefficient }\end{array}$ & $\begin{array}{l}\text { Number } \\
\text { of Items }\end{array}$ \\
\hline Positive Emotion & $\alpha=0.673$ & 3 \\
\hline Engagement & $\alpha=0.408$ & 2 \\
\hline Relationship & $\alpha=0.656$ & 3 \\
\hline Meaning & $\alpha=0.705$ & 3 \\
\hline Accomplishment & $\alpha=0.747$ & 2 \\
\hline
\end{tabular}


The Short Index of Self-Actualization. This research used the Short Index of SelfActualization (Jones \& Crandall, 1986) to measure self-actualization. The scale can be used when time is limited or when there is no concern for the sub-aspects of self-actualization (Faraci \& Cannistraci, 2015). The scale has a six point Likert scale from strongly disagree (1) to strongly agree (6). This instrument originally had 15 items with an alpha of 0.65 according to Jones and Crandall (in Faraci \& Cannistraci, 2015). However, eight items were removed from the scale because of low validity. The reliability of the remaining seven items was $\alpha=$ $0.688(M=24.04, S D=5.030)$.

\section{Data Analysis Technique}

Simple linear regression analysis and the Statistical Program for Social Sciences (SPSS) 14.0 for Windows were used to analyze the data. Reliability was tested using Cronbach's alpha analysis.

\section{Results}

It was found that self-actualization significantly and negatively contributed to all flourishing a dimensions; $18.3 \%$ to Positive emotion ( $\left.\mathrm{p}=0.000, \mathrm{R}^{2}=0.183, \mathrm{~B}=-0.148\right), 15.4 \%$ to Engagement $\left(\mathrm{p}=0.000, \mathrm{R}^{2}=0.154, \mathrm{~B}=-0.94\right), 16.6 \%$ to Relationship $\left(\mathrm{p}=0.000, \mathrm{R}^{2}=0.166, \mathrm{~B}=-\right.$ $0.192), 19.7 \%$ to Meaning ( $\mathrm{p}=0.000, \mathrm{R}^{2}=0.197, \mathrm{~B}=-0.195$ ), and $15.4 \%$ to Accomplishment $\left(\mathrm{p}=0.000, \mathrm{R}^{2}=0.154, \mathrm{~B}=-0.119\right)$. A majority of the participants $(55.1 \%)$ were found to have a high self-actualization tendency $(\mathrm{M}=24.04)$.

\section{Discussion and Conclusion}

These results supported the hypothesis that self-actualization makes a significant contribution to the flourishing (PERMA) dimensions; however, as all these contributions were found to be negative, these results did not support Lent's (in Cooke, Melchert, \& Connor, 2016) claims that psychological health can be developed by actualizing an individual's potential.

This study found that self-actualization negatively contributed to Positive emotion ( $\mathrm{p}=0.000$, $\left.\mathrm{R}^{2}=0.183, \mathrm{~B}=-0.148\right)$ and that most participants (55.1\%) had high self-actualization tendencies $(\mathrm{M}=24.04)$. Research on emotions has explained basic emotions such as happiness, sadness, anger, fear, and disgust (Ekman \& Friesen, in [14]); however, the PERMA-Profiler of Positive emotions measures general tendencies toward feelings of contentment and joy (Butler $\&$ Kern, 2016). The significant and negative contribution of self-actualization toward positive emotion may be because of contextual factors such as culture as all participants came from interdependent collectivist Indonesian ethnicities (Markus \& Kitayama, 1991; Larsen \& Buss, 2008). Markus \& Kitayama (1991) claimed that interdependency in non-western cultures can influence emotion. Therefore, while the study participants had high self-actualization tendencies, the motivation to actualize their potential may have had a negative influence on their positive emotions because self-actualization characteristics such as higher autonomy and individuality may be incongruous with interdependency if their cultures constrain personal desires. 
The result of this study showed that Self-actualization was found to significantly and negatively contribute to the Engagement dimension $\left(p=0.000, R^{2}=0.154, \quad B=-0.94\right)$. Engagement is experienced when an individual fully uses their skills, strength, and attention for a challenging task to produce "flow." Individuals experience flow when they are fully absorbed in an activity and experience a distortion in their time perception (Seligman, 2011). Psychological engagement in flow is characterized by intense concentration and absorption (Butler \& Kern, 2016), which produce feelings of pleasure (Csikszentmihalyi (as cited in Brown \& Ryan, 2003)). Self-actualization can have a negative influence on engagement if individuals focus too much on their future goals to actualize their potential. When people are preoccupied with the future, it can lessen their engagement with the present (Brown \& Ryan, 2003), which is important to engendering engagement.

Self-actualization was found to have a significant but negative contribution to the Relationship dimension $\left(\mathrm{p}=0.000, \mathrm{R}^{2}=0.166, \mathrm{~B}=-0.192\right)$. Self-actualized people have been found to maintain a degree of individuality and detachment especially in interdependent collectivist cultures such as Indonesia in which the people tend to view themselves as being connected to groups (Triandis (as cited in Larsen \& Buss, 2008)). Therefore, people with higher selfactualization tend to be viewed as individuals and as being less connected to the group, which could have a negative influence on their relationships with other people.

This study showed that selfSelf-actualization was also found to have a significant but negative contribution to the Meaning dimension $\left(\mathrm{p}=0.000, \mathrm{R}^{2}=0.197, \mathrm{~B}=-0.195\right)$. Meaning refers to serving and belonging to something bigger than the self to give life a sense of meaning. Various social institutions have been found to give meaning and purpose to people, such as religion, family, and work (Seligman, 2011). People with higher self-actualization tend to create meaning in their activities that is independent of extrinsic satisfaction and emphasizes inner satisfaction; that is, the determinants of satisfaction are inner-individual and not social (Maslow, 1987). Collectivist societies tend to be more concerned about relationships and less likely to emphasize personal goals (Triandis (as cited in Larsen \& Buss, 2008)). Therefore, self-actualization can have negative contribution toward meaning if the activities to create meaning in life are directed to fulfill individual inner satisfaction rather than group satisfaction.

Self-actualization was also found to negatively contribute to the Accomplishment dimension $\left(\mathrm{p}=0.000, \mathrm{R}^{2}=0.154, \mathrm{~B}=-0.119\right)$. Self-actualized people pursue achievement, competence, success, and mastery in various areas of their life to realize their potential. In the flourishing Accomplishment dimension, the accomplishment is pursued for its own sake (Seligman, 2011). However, as individuals in collectivist society tend to view themselves as being connected to groups, the group goals are more important than the personal goals (Triandis (as cited in Larsen \& Buss, 2008)). Therefore, if self-actualized people try to pursue their goals only to get rewards from their group, rather than pursuing their goals to realize their true nature or self-fulfillment, the self-actualization could have a negative influence on accomplishment. 
The suggestions in previous studies that tested the psychometric properties in different cultures. Cooke, Melchert, and Connor (2016), for example, found that typical well-being measures tended to have a western individualistic orientation. Another explanation is that different views of the self across cultures may affect the need of self-actualization (Markus \& Kitayama, 1991; Faraci \& Cannistraci, 2015). Although the Short Index of Self-Actualization has been used widely to test various theories, further study on the structure and consistency of the instrument for use in different cultures and languages could contribute to developing theories about the dimensionality of the construct and to develop a more reliable and valid instrument (Faraci \& Cannistraci, 2015).

This study's limitations might be related with the measurement. Psychometric studies using the Short Index of Self-Actualization are needed because of the relatively moderate Cronbach alpha $(\alpha=0.688)$. Faraci and Cannistraci (2015) found that the Cronbach's alpha for the 15 items in the Short Index of Self-Actualization was $\alpha=0.526$ in their psychometric study, and also found that the internal consistency did not increase even after items were deleted. Therefore, based on the results of this study and previous research, this scale must be used with an awareness of psychometric issues. Further psychometric research is needed to study the measurement of self-actualization within Maslow's theoretical model.

Another limitation in this study was that the analysis on the contribution of self-actualization to the Engagement and Accomplishment dimensions was assessed using only two items in each dimension that had only low to moderate alphas. Further studies are therefore still needed to provide a better scale item construction.

Thus, more research is needed on the relationship between flourishing and self-actualization. The negative contribution of self-actualization to all flourishing dimensions may be related to the tendency in highly self-actualized people to maintain their individuality even in interdependent collectivist cultures, to be more concerned with the future than fully engaging in the present moment, and to pursue goals to get rewards from their group rather than to realize their true nature or self-fulfillment. Further study is still needed to provide a better analysis and construction of the items and the scale to develop items that have higher validity and reliability regarding the differences in the population sample characteristics.

\section{References}

Brown, K. W. \& Ryan, R. M. (2003). The benefits of being present: Mindfulness and its role in psychological well-being. Journal of Personality and Social Psychology, 84(4), 822-848.

Butler, J. \& Kern, M. L. (2016). The PERMA-Profiler: A brief multidimensional measure of flourishing. International Journal of Wellbeing, 6(3), 1-48.

Cooke, P. J., Melchert, T. P., \& Connor, K. (2016). Measuring well-being: A review of instruments. The Counseling Psychologist, 44(5), 730-757.

Danner, D. D., Snowdon, D. A., \& Friesen, W. A. (2001). Positive emotions in early life and longevity: Findings from the nun study. Journal of Personality and Social Psychology, 80(5), 804-813. 
Diener, E., \& Seligman, M. E. (2004). Beyond money: Toward an economy of well-being. Psychological science in the public interest, 5(1), 1-31.

Faraci, P. \& Cannistraci, S. (2015). The short index of self-actualization: A factor analysis study in an Italian sample. International Journal of Psychological Research, 8(2), 23-33.

Hone, L. C., Jarden, A., Schofield, G. M., Duncan, S. (2014). Measuring flourishing: The impact of operational definitions on the prevalence of high levels of well-being. International Journal of Wellbeing, 4(1), 6290.

Jones, A. \& Crandall, R. (1986). Validation of a short-index of self-actualization. Personality and Social Psychology Bulletin, 12(1), 63 -73.

Larsen, R. J. \& Buss, D. M. (2008). Personality psychology: Domains of knowledge about human nature (3rd ed.). Boston: McGraw-Hill.

Markus, H. R. \& Kitayama, S. (1991). Culture and the self: Implications for cognition, emotion, and motivation. Psychological Review, 98(2), 224-253.

Maslow, A. H. (1987). Motivation and personality (3rd ed.). New York: Harper \& Row, Publishers, Inc.

Ryff, C. D. \& Keyese, C. L. M. (1995). The structure of psychological well-being revisited. Journal of Personality and Social Psychology, 69(4), 719-727.

Schotans-Dijkstra, M., Pieterse, M. E., Drossaert, C. H. C., Westerhof, G. J., Graaf, D. R., Have, T. M., \& Bohlmeijer, E. T. (2016). What factors are associated with flourishing? Results from a large representative national sample. Journal of Happiness Studies, 17(4), 1351-1370.

Seligman, M. E. P. (2011). Happiness is not enough. Authentic Happiness. Retrieved from https://www.authentichappiness.sas.upenn.edu/newsletters/flourishnewsletters/newtheory.

Seligman, M. E. P. \& Csikszentmihalyi, M. (2014). Positive psychology. An introduction. American Psychologist, 55(1), 5-14. 